\title{
Electrochromic Window with Lithium Conductive Polymer Electrolyte
}

\author{
Paul Baudry* and Michel André Aegerter \\ Instituto de Fisica e Quimica de São Carlos, University of São Paulo, C.P. 369, 13560 Sao Carlos, Brazil \\ Daniel Deroo and Bruno Valla \\ Laboratoire d'Ionique et d'Electrochimie du Solide, ENSEEG, B.P. 75, 38402 St. Martin-d'Heres, France
}

\section{ABSTRACT}

An electrochromic window was built using $\mathrm{WO}_{3}$ as electrochromic material and $\mathrm{V}_{2} \mathrm{O}_{5}$ as counterelectrode. Both were deposited onto ITO-coated glass panes by vacuum evaporation and were amorphous to x-ray diffraction. The electrolyte was a lithium-conducting polymer consisting of a poly(ethylene oxide)-lithium salt complex. The electrochemical characterization of electrodes was realized by cyclic voltammetry, coulometric titration, and impedance spectroscopy, which allowed the determination of the chemical diffusion coefficients of lithium into $\mathrm{WO}_{3}$ and $\mathrm{V}_{2} \mathrm{O}_{5}$. Potentiostatic cycling of the complete transmissive cell yields to a transmission variation from 41 to $13 \%$ at $633 \mathrm{~nm}$ with a response time of $10 \mathrm{~s}$ at room temperature.

Over the last two decades, much work has been dedicated to the study of electrochromism for its possible application in electro-optical devices $(1,2)$. However, some major problems such as slow switching time or layer corrosion have been encountered. Nevertheless, the realization of energy-efficient windows emerged a few years ago as a new interesting application in that field $(3,4)$. In this latter kind of device, a response time of approximately $1 \mathrm{~min}$, easily attainable, is sufficient, and the memory effect provided by the electrochemical reaction is of great interest.

Many insertion materials, e.g., metal transition oxides, exhibit electrochromic properties when deposited in thin films. Their optical properties are modified by electrochemical insertion of alkali cations or protons. The corresponding reaction can be written as

$$
y A^{+}+y e^{-}+\mathrm{MO}_{x} \rightarrow \mathrm{A}_{y} \mathrm{MO}_{x}
$$

Tungsten trioxide has been the most investigated electrochromic material $(5,6)$ and without any doubt is one of the most promising with respect to its electrochromic properties. Both proton and lithium insertion are possible. Although the chemical diffusion coefficient of $\mathrm{H}^{+}$in $\mathrm{WO}_{3}$ is higher than that of $\mathrm{Li}^{+}(7)$, it seems easier to realize a complete transmissive electrochromic device with lithium conductors than with protonic ones, as hydrogen gassing and layer corrosion in acid media are potential drawbacks in the protic system.

Polymer electrolytes have been widely studied during the last ten years for high energy secondary solid-state batteries $(8,9)$. Their use in electrochromic devices is suitable since they can be fabricated as thin elastomeric films, and do not present problems of leakage encountered with liquid electrolytes. Polyethylene oxide (PEO) complexes exhibit conductivities higher than $10^{-5} \Omega^{-1} \mathrm{~cm}^{-1}$ with both lithium and proton conduction $(10,11)$, giving rise to a fast switching time.

Whereas the electrochromic material and a solid electrolyte are available, a suitable transparent counterelectrode is still to be found. Two different types of counterelectrode can be considered. It may be transparent in both oxidized and reduced states, but a "rocking chair" counterelectrode occurring at the same time as the electrochromic electrode may also be envisaged. In this case, the counterelectrode will color anodically if $\mathrm{WO}_{3}$ is used as electrochromic material. For example, $\mathrm{IrO}_{2}$ has been successfully used with protonic conduction (12).

In this work, a $\mathrm{Li}_{x} \mathrm{WO}_{3}$ /ithium-conducting polymer electrolyte $/ \mathrm{Li}_{x} \mathrm{~V}_{2} \mathrm{O}_{5}$ electrochromic window is investigated. $\mathrm{V}_{2} \mathrm{O}_{5}$ has been selected as a counterelectrode because it is a good lithium insertion material and is fairly transparent as

* Electrochemical Society Active Member. a thin film (12-15). The reversible insertion reaction can be written as follows

$$
\mathrm{V}_{2} \mathrm{O}_{5}+y \mathrm{Li}^{+}+y e^{-} \rightarrow \mathrm{Li}_{y} \mathrm{~V}_{2} \mathrm{O}_{5}
$$

Individual layers have been characterized by SIMS, cyclic voltammetry, and impedance spectroscopy. Potentiostatic cycling coupled with transmittance measurement was performed at room temperature on the complete device in order to evaluate the performance of the cell.

\section{Experimental}

Layer preparation.-Both $\mathrm{WO}_{3}$ and $\mathrm{V}_{2} \mathrm{O}_{5}$ layers were deposited from the corresponding oxide powder by vacuum evaporation onto $0.4 \mu \mathrm{m}$ thick indium tin oxide. (ITO) coated glass. These films were amorphous to x-ray diffraction. Their thickness, measured by a Talystep with an accuracy of $\pm 10 \mathrm{~nm}$, was $220 \mathrm{~nm}$ for $\mathrm{V}_{2} \mathrm{O}_{5}$ and varied from 200 to $300 \mathrm{~nm}$ for $\mathrm{WO}_{3}$. The films were electrochemically characterized as deposited without any heat-treatment.

The polymer electrolyte was a polyethylene oxide-LiX complex $\left(\mathrm{X}=\mathrm{ClO}_{4}, \mathrm{~N}\right.$ - $\left.\left(\mathrm{SO}_{2} \mathrm{CF}_{3}\right)_{2}\right)$ prepared by dissolving PEO powder (m.w. $\left.=5 \cdot 10^{6}\right)$ and the lithium salt in acetonitrile, with a $\mathrm{O}: \mathrm{Li}$ atomic ratio of $8: 1$, giving rise to the highest conductivity in these systems $(9,10)$. This viscous complex was doctor-bladed on a polytetrafluoroethylene substrate. Then, the solvent was evaporated at $70^{\circ} \mathrm{C}$ for $24 \mathrm{~h}$. The polymer films were kept in a dry box $(<1 \mathrm{ppm}$ $\mathrm{H}_{2} \mathrm{O}$ ) in order to eliminate any residual solvent or moisture. Elastomeric thin films $(50-200 \mu \mathrm{m})$ were thus obtained.

Secondary ion mass spectroscopy (SIMS).-Profiles of lithium concentration within the electrode layers were measured by SIMS at different insertion rates. For this purpose a previous electrochemical insertion was made in

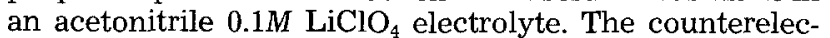
trode was a platinum foil and the reference was a silver wire immersed in an acetonitrile $0.01 \mathrm{M} \mathrm{AgNO}$ solution. The reference compartment was separated from the main cell by a fritted glass tube. The potentiostatic mode was preferred to the galvanostatic, to realize the reduction in order to avoid any side reaction. The potential applied was $-1.5 \mathrm{~V} / \mathrm{Ag}$. The SIMS experiments were performed with a $5.5 \mathrm{keV} \mathrm{O}{ }_{2}{ }^{+}$beam and an intensity of $30 \mathrm{nA}$.

Electrochemical experiments.-Cyclic voltammetry, coulometric titration, and ac impedance measurements were performed with a $\mathrm{PEO}-\mathrm{LiClO}_{4}$ polymer electrolyte. The cells were hot-pressed at $80^{\circ} \mathrm{C}$ in the dry box and sealed with a low vapor pressure paste (Varian Torr-seal).

A $1.6 \mathrm{~cm}$ diam lithium disk covered by stainless steel was used as counter and reference electrode in the cyclic voltammetry and coulometric titration cells. The use of the same electrode as counter and reference electrodes was justified by the low polarizability of the lithium, especially 


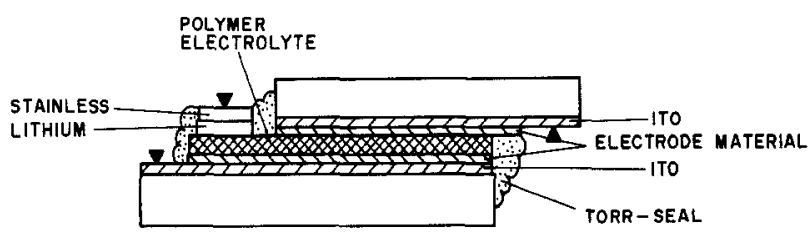

Fig. I. Experimental setup for impedance measurements with PEO$\mathrm{LiClO}_{4}$ polymer electrolyte.

at high temperature and with low currents flowing through the cell. The ac impedance spectroscopy was realized with a two-electrode configuration as shown in Fig. 1. Working and counterelectrodes were constituted by the same material with the same insertion rate. A lithium reference was placed beside the working electrode in order to control the potential and to allow reduction of both counter and working electrodes to the same potential before executing the impedance measurements. After reaching equilibrium, i.e., the stabilization of potential, a small alternating voltage was applied between the two electrodes. The impedance was measured with a frequency response analyzer (Solartron 1250) coupled to an Apple IIC calculator in the frequency range $6 \cdot 10^{4}-10^{-3} \mathrm{~Hz}$ at several temperatures. In this configuration, the measured impedance is the sum of the working electrode, counterelectrode, and electrolyte impedances.

For the cycling tests, it is necessary to reduce either the $\mathrm{WO}_{3}$ or $\mathrm{V}_{2} \mathrm{O}_{5}$ electrode before assembling the cell in order to obtain a lithium reservoir. Although this reduction can be made chemically, for example by reaction with $n$ butyl lithium in a nonpolar solvent like cyclohexane, the electrochemical way was preferred. It provides a more homogeneous and faster coloration, and the insertion rate can be controlled. In this complete window, the electrolyte was a PEO-LiN $\left(\mathrm{SO}_{2} \mathrm{CF}_{3}\right)_{2}$ complex, which is more conductive and transparent than the $\mathrm{PEO}-\mathrm{LiClO}_{4}$ electrolyte at room temperature due to a lower glass transmission temperature (10). This transmissive device was also hotpressed and sealed in the dry box in order to avoid any moisture contamination. Its optical transmission was measured at $633 \mathrm{~nm}$ (He-Ne laser) simultaneously with the current flowing through the cell.

\section{Results and Discussion}

The $\mathrm{WO}_{3}$ and $\mathrm{V}_{2} \mathrm{O}_{5}$ layers were analyzed by the SIMS technique at different insertion rates. The profiles of lithium concentration in these layers are represented in Fig. 2 and 3 . The concentration gradient of lithium in $\mathrm{WO}_{3}$ is low until the $\mathrm{WO}_{3} / \mathrm{ITO}$ interface and very high in ITO. This means that the lithium diffusion in ITO is very slow. In

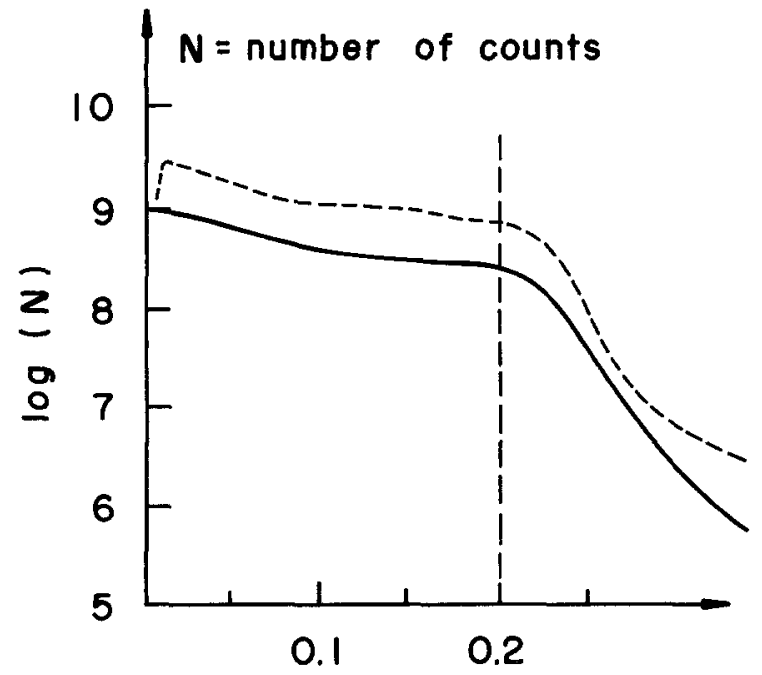

THICKNESS $(\mu \mathrm{m})$

Fig. 2. Profile of lithium concentration in $\mathrm{WO}_{3}$ by SIMS: $12.2 \mathrm{mC} / \mathrm{cm}^{2}$; (----) $22 \mathrm{mC} / \mathrm{cm}^{2}$.

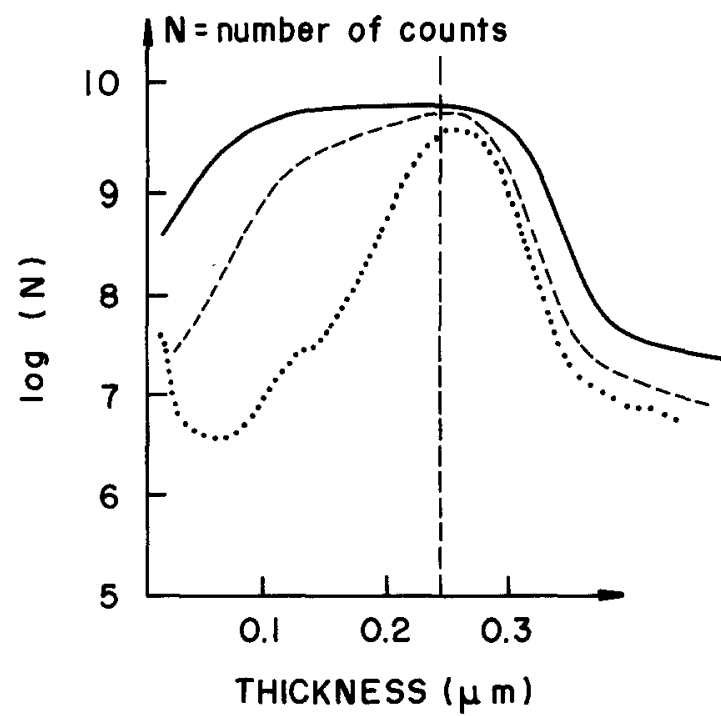

Fig. 3. Profile of lithium concentration in $\mathrm{V}_{2} \mathrm{O}_{5}$ by SIMS: (-) $19.4 \mathrm{mC} / \mathrm{cm}^{2}$; (.-) $10.6 \mathrm{mC} / \mathrm{cm}^{2} ;(\ldots \ldots) 6.2 \mathrm{mC} / \mathrm{cm}^{2}$.

both bases the lithium concentration increases with the charge passed through the cell as expected. However, the values of the lithium concentration obtained for both materials cannot be compared quantitatively because their erosion rate by the incident beam are different.

Figures 4 and 5 show the cyclic voltammetries obtained at $80^{\circ} \mathrm{C}$ with $\mathrm{PEO}-\mathrm{LiClO}_{4}$ electrolyte for the $\mathrm{WO}_{3}$ voltammogram is the same as that obtained with a liquid electrolyte. Even at low sweep rate, no insertion peak has been observed. Armand (16) reported that this peak is located at $1.5 \mathrm{~V} / \mathrm{Li}$. This potential value is outside the scanned range because the stability threshold of ITO is approximate $1.7 \mathrm{~V} / \mathrm{Li}$. It is also well known that crystalline $\mathrm{V}_{2} \mathrm{O}_{5}$ exhibits in cyclic voltammetry three well-defined peaks corresponding to three different phases (17). In the $\mathrm{V}_{2} \mathrm{O}_{5}$ voltammogram of Fig. 5 , we only observe one peak at $2 \mathrm{~V} / \mathrm{Li}$ and a broad shoulder at $3 \mathrm{~V} / \mathrm{Li}$. This behavior is therefore characteristic of an amorphous electrode.

The thermodynamic curves of Fig. 6 and 7 have been obtained by coulometric titration, i.e., a succession of galvanostatic pulses and potential equilibration. Once more, we can observe an amorphous electrode behavior without any plateau, as would be expected with a multiphase electrode material. The available insertion rate above $2 \mathrm{~V} / \mathrm{Li}$ obtained by calculating the number of lithium ions inserted by metal atom is 0.8 for $\mathrm{WO}_{3}$ and 0.9 for $\mathrm{V}_{2} \mathrm{O}_{5}$. These values are in good agreement with those reported by Mohapatra and Wagner (18) for amorphous $\mathrm{WO}_{3}$ in liquid electrolyte and by Nabavi et al. (19) for amorphous bulk $\mathrm{V}_{2} \mathrm{O}_{5}$ electrode.

The ac response of an electrochemical system with either charge transfer or diffusion-limited kinetics has been

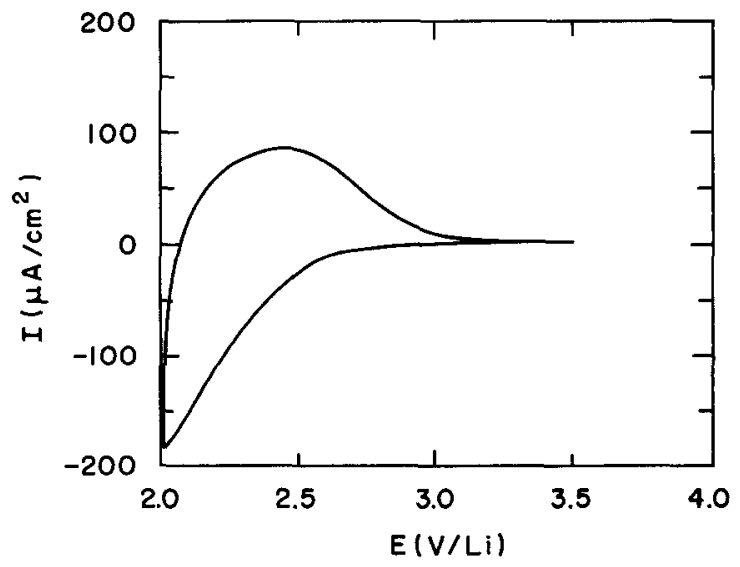

Fig. 4. Cyclic voltammetry of a $300 \mathrm{~nm}$ thick $\mathrm{WO}_{3}$ electrode PEO$\mathrm{LiClO}_{4}$ electrolyte: $T=80^{\circ} \mathrm{C}$, sweep rate $300 \mathrm{mV} / \mathrm{s}$. 


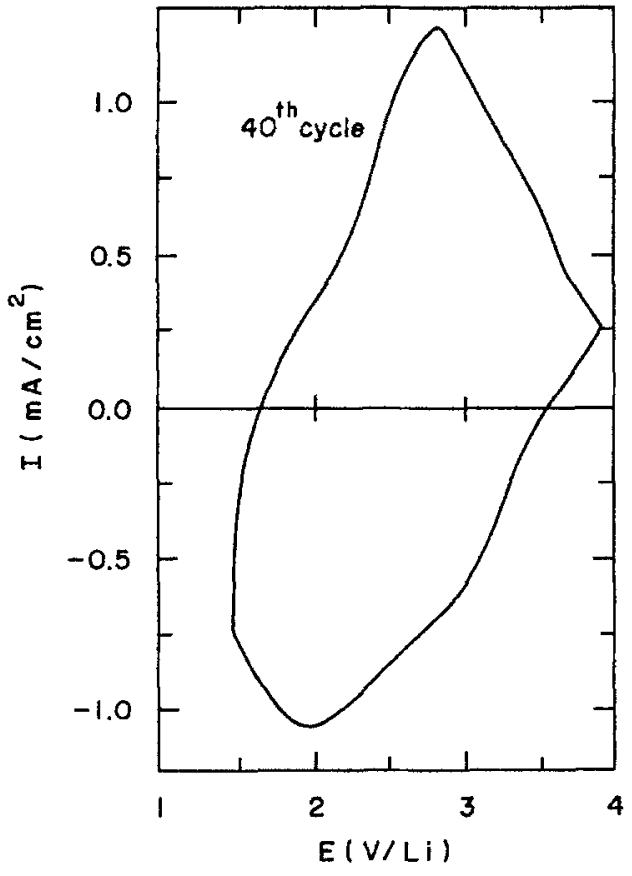

Fig. 5. Cyclic voltammetry of a $220 \mathrm{~nm}$ thick $\mathrm{V}_{2} \mathrm{O}_{5}$ electrode PEO$\mathrm{LiClO}_{a}$ electrolyte: $T=80^{\circ} \mathrm{C}$, sweep rate $1000 \mathrm{mV} / \mathrm{s}$.

analyzed by Randles (20), with the equivalent circuit shown in Fig. 8, applied by Ho et al. (21) to the case of lithium insertion in amorphous $\mathrm{WO}_{3}$ with a liquid electrolyte. In this figure, $R_{E}$ is the ohmic resistance of the electrolyte, $R_{C T}$ is the charge transfer resistance, $C_{D L}$ is the double layer capacitance of the electrode/electrolyte interface, and $Z_{D}$ is a complex impedance arising from the diffusion of lithium ions. The charge transfer resistance $R_{C T}$ is related to the exchange current density $i_{0}$ through a linearization of the Butler-Volmer equation for small overpotentials (22)

$$
\mathrm{R}_{\mathrm{CT}}=R T /\left(z \mathbf{F} i_{\mathrm{o}} S\right)
$$

where $R$ is the gas constant, $T$ is the temperature, $z$ is the charge of the inserted cation, $\mathbf{F}$ is the Faraday constant, and $S$ is the surface area. The expression for $Z_{\mathrm{D}}$ can be obtained by the resolution of the Fick equation with suitable initial and boundary conditions

$$
Z_{\mathrm{D}}=\frac{L V_{\mathrm{M}}(d E / d y)_{y_{\mathrm{o}}}}{z \tilde{F} \tilde{\mathrm{D}} S} \frac{1}{u} \operatorname{coth} u
$$

with $u=L(j \omega / \tilde{D})$ and where $j=V-1, L$ is the film thickness, $V_{M}$ is the molar volume, $\widetilde{D}$ is the chemical diffusion coefficient, $(d E / d y)_{y_{0}}$ is the slope of the coulometric titration curve at the insertion rate $y_{0}$, and $\omega$ is the radial frequency.

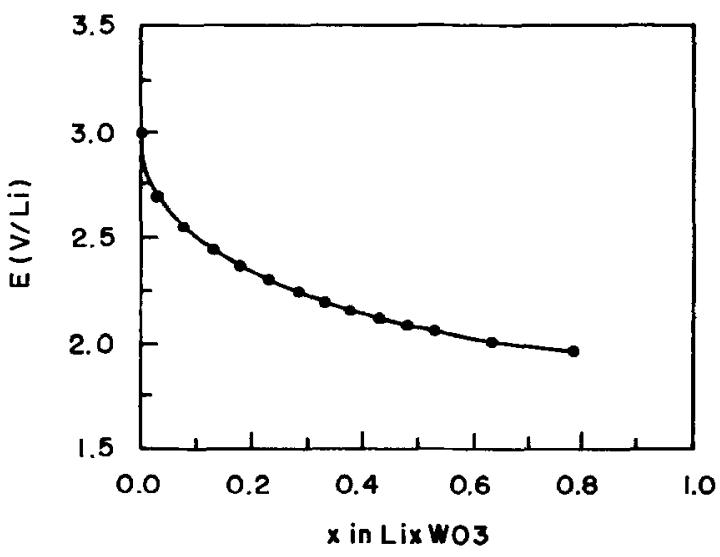

Fig. 6. Coulometric titration curve for $\mathrm{WO}_{3}$ electrode PEO-LiClO electrolyte, $T=80^{\circ} \mathrm{C}$.

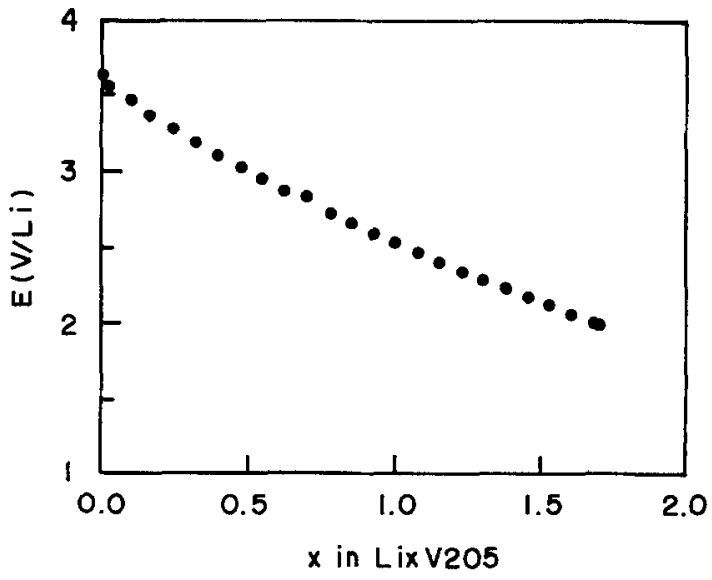

Fig. 7. Coulometric titration curve for $\mathrm{V}_{2} \mathrm{O}_{5}$ electrode $\mathrm{PEO}-\mathrm{LiClO}_{4}$ electrolyte, $T=80^{\circ} \mathrm{C}$.

The $\mathrm{WO}_{3}$ and $\mathrm{V}_{2} \mathrm{O}_{5}$ impedance data shown in Fig. 9 and 10 have been plotted in the Nyquist plane at different temperatures. The semicircle observed at high frequencies, which is related to the charge transfer process, is well separated from the low-frequency part of the diagram corresponding to the lithium diffusion into the electrode material. Therefore, the charge transfer resistance, and consequently, the exchange current density through Eq. [1], have been calculated at different temperatures and are shown in Fig. 11. At low temperature, $i_{\mathrm{o}}$ is small and the charge transfer process may be the limiting step for fast switching times. This emphasizes the problem of a solid/solid interface and the importance of a good electrolyte/electrode contact. Ho et al. (21) have considered two extreme cases for the determination of the chemical diffusion coefficient: (i) When $\widetilde{D} / \omega L^{2}<<1$, the semi-infinite diffusion conditions are fulfilled giving rise to the Warburg impedance

$$
Z_{\mathrm{D}}=\frac{V_{\mathrm{M}}(d E / d y)}{\sqrt{2} z \mathbf{F} \bar{D}^{1 / 2} S} \omega^{-1 / 2}(1-j)
$$

The current is $\pi / 4$ out of phase with the voltage, and $\tilde{D}$ can be calculated if $S$ and $d E / d y$ are known. (ii) When $\bar{D} / \omega L^{2}<<1$, the homogeneous diffusion regime is obtained. Under this condition, the real part of the impedance $\operatorname{Re}(Z)$ is independent of the frequency

$$
\operatorname{Re}(Z)=\frac{V_{\mathrm{M}} L}{3 z \mathbf{F} \tilde{D} S}
$$

Thus, the phase difference between the current and the voltage is equal to $\pi / 2$, and $\widetilde{D}$ can be calculated without the knowledge of $S$ and $(d E / d y)$ by the relation

$$
\widetilde{D}=\frac{L^{2} \omega}{3 \operatorname{Re}(Z)} \operatorname{Im}(Z)
$$

where $\operatorname{Im}(Z)$ is the imaginary part of the impedance. It must be pointed out that only the diffusion part must be taken into account for $\operatorname{Re}(Z)$.

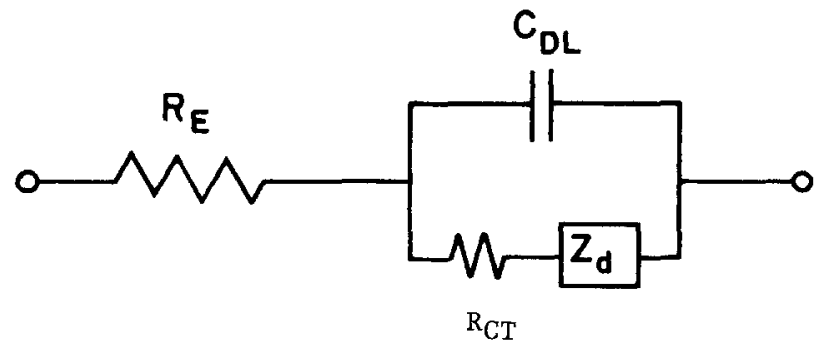

Fig. 8. Randles equivalent circuit 

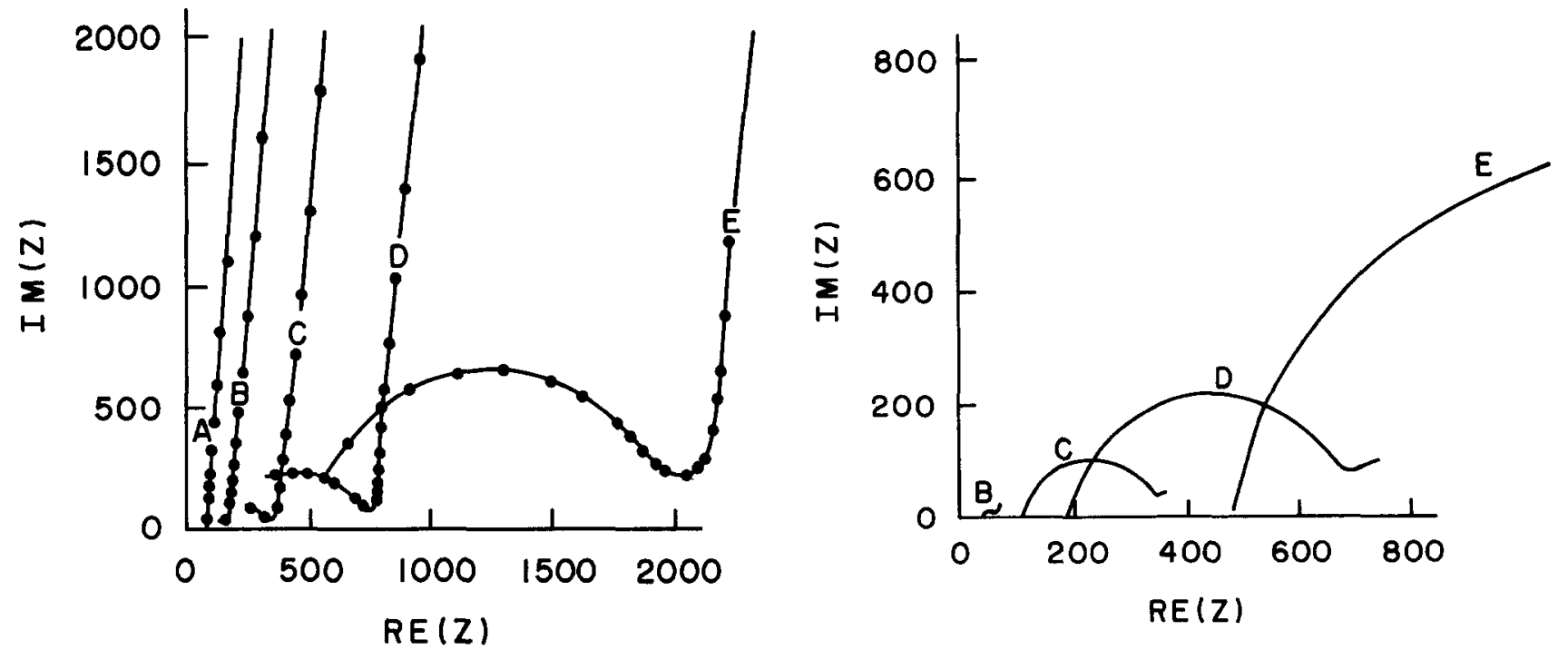

Fig. 9. Complex impedance data for $200 \mathrm{~nm}$ thick $\mathrm{WO}_{3}$ electrode PEO-LiClO ${ }_{4}$ electrolyte: (a, left) low-frequency plot, and (b, right) high-frequency plot. A. $81^{\circ} \mathrm{C}, \mathrm{B} .65^{\circ} \mathrm{C}, \mathrm{C} .55^{\circ} \mathrm{C}, \mathrm{D}, 45^{\circ} \mathrm{C}$, and $\mathrm{E} .36^{\circ} \mathrm{C}$.
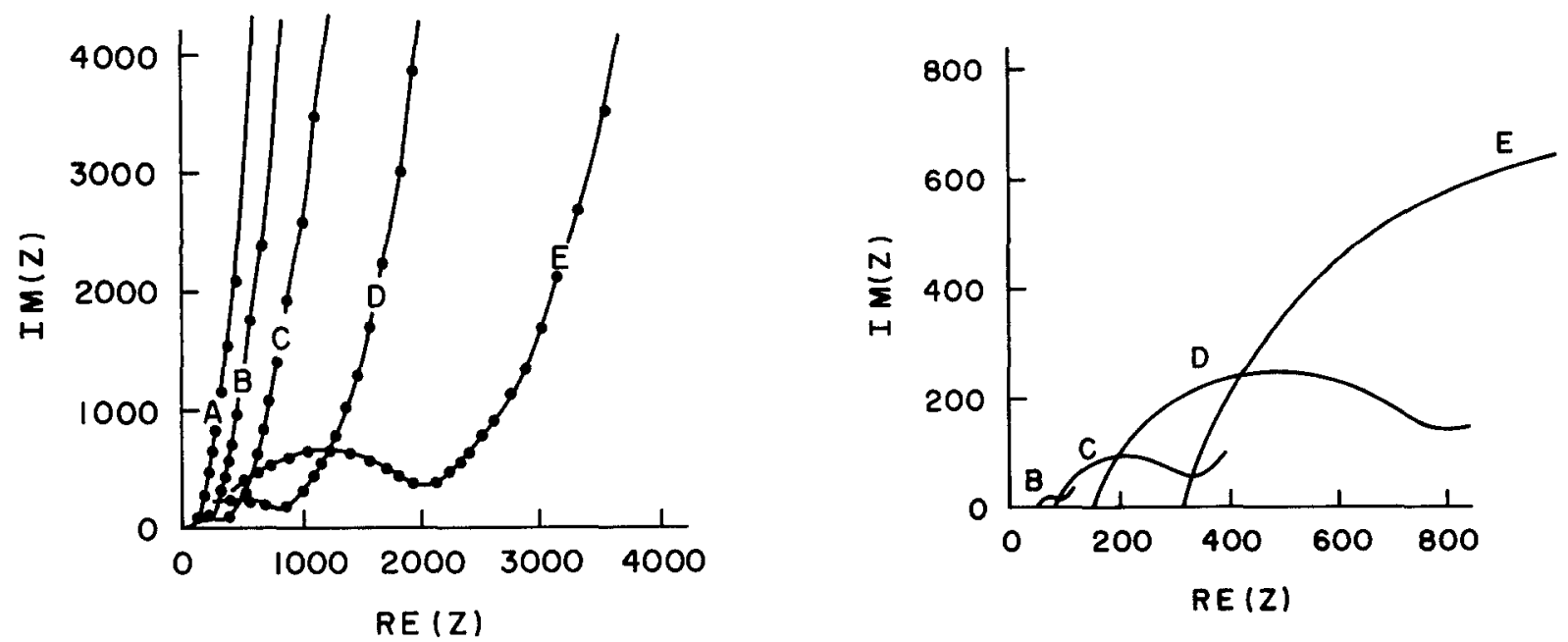

Fig. 10. Complex impedance data for $220 \mathrm{~nm}$ thick $\mathrm{V}_{2} \mathrm{O}_{5}$ electrode PEO-LiClO ${ }_{4}$ electrolyte: (a, left) low-frequency plot, and (b, right) high-frequency plot. A. $87^{\circ} \mathrm{C}, \mathrm{B} .74^{\circ} \mathrm{C}, \mathrm{C} .66^{\circ} \mathrm{C}, \mathrm{D} .55^{\circ} \mathrm{C}$, and E. $45^{\circ} \mathrm{C}$.

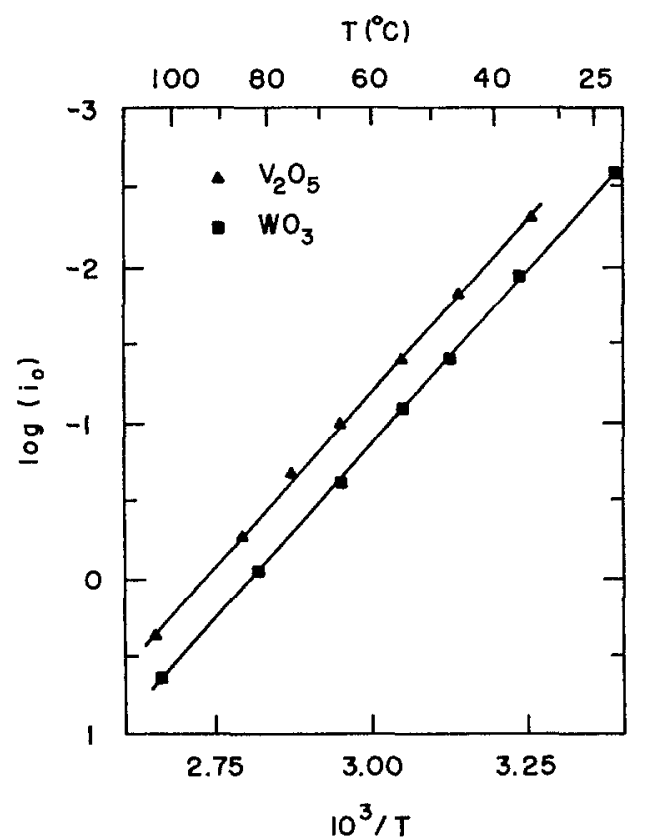

Fig. 11. Temperature dependence of $i_{0}$ with $\mathrm{PEO}-\mathrm{LiClO}_{4}$ electrolyte for $\mathrm{WO}_{3}$ and $\mathrm{V}_{2} \mathrm{O}_{5}$ electrodes.
These two limiting cases are theoretically very convenient for the determination of $\bar{D}$. However, they are not easy to use with the impedance diagrams that we obtained. On one hand, the Warburg portion is small and probably hidden in the charge transfer zone. On the other hand, the accuracy in the determination of $\operatorname{Re}(Z)$ in the low-frequency part is very poor. Actually, the impedance is not purely capacitive, and $\operatorname{Re}(Z)$ is slightly dependent on the frequency. This can be attributed to a dispersion phenomenon due to a weak lithium diffusion from $\mathrm{WO}_{3}$ into ITO or a contact loss at the electrolyte/electrode interface, giving rise to a nonplanar electrode. Therefore, we have considered the intermediate case where $\bar{D} / \omega L^{2}$ is close to 1 . Equation [2] enables a direct relation between the phase and $\tilde{D} / \omega L^{2}$ as shown in Fig. 12. In the range of intermediate frequencies, the phase variation is large, increasing the accuracy. Thus, $\bar{D}$ has been calculated for a phase equal to $\pi / 3$. The temperature dependence of the lithium chemical diffusion coefficient in $\mathrm{WO}_{3}$ and $\mathrm{V}_{2} \mathrm{O}_{5}$ obtained by this method is shown in Fig. 13. This yields values of $2.5 \times 10^{-11} \mathrm{~cm}^{2} / \mathrm{s}$ for $\mathrm{WO}_{3}$ at $2.4 \mathrm{~V} / \mathrm{Li}$ and $2.5 \times 10^{-12} \mathrm{~cm}^{2} / \mathrm{s}$ for $\mathrm{V}_{2} \mathrm{O}_{5}$ at $3 \mathrm{~V} / \mathrm{Li}$ at $25^{\circ} \mathrm{C}$. These values have to be compared with those determined also by impedance spectroscopy but with a liquid electrolyte. Ho et al. (21) reported a $\bar{D}$ value of $1.5 \times 10^{-11} \mathrm{~cm}^{2} / \mathrm{s}$ at the same voltage in propylene carbonate-LiAsF $F_{6}$ solution for $\mathrm{WO}_{3}$, and Zachau et al. (23) obtained $\widetilde{D}=6.3 \times 10^{-12} \mathrm{~cm}^{2} / \mathrm{s}$ with crystallized $\mathrm{V}_{2} \mathrm{O}_{5}$ in propylene carbonate- $\mathrm{LiClO}_{4}$ at $2.8 \mathrm{~V} / \mathrm{Li}$. Agreement is good 


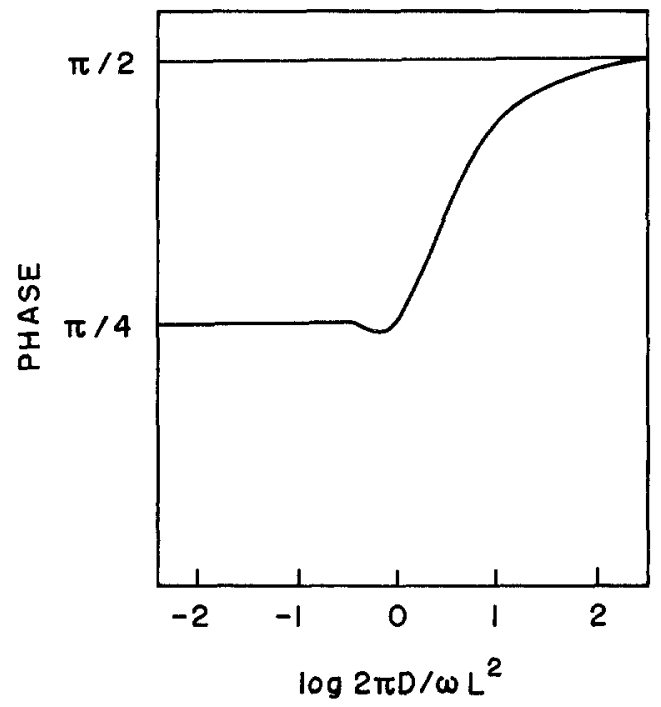

Fig. 12. Relation between the impedance phase and $\widetilde{D}$ calculated through Eq. [2].

even though the method does not take into account the surface area. Therefore, the main modification introduced by the presence of a solid/solid interface involves only the charge transfer process, whereas the diffusion kinetics is the same as with a liquid electrolyte.

The 10,000 th cycle of a potentiostatic test carried out with a $\mathrm{WO}_{3} / \mathrm{PEO}-\mathrm{LiN}\left(\mathrm{SO}_{2} \mathrm{CF}_{3}\right)_{2} / \mathrm{V}_{2} \mathrm{O}_{5}$ electrochromic window at room temperature is shown in Fig. 14. The optical transmission at $633 \mathrm{~nm}$ varies from $41 \%$ in the bleached state to $13 \%$ in the colored state with a time response of 10 s. The major drawback remains the low optical transmission value in the bleached state.

\section{Conclusion}

The use of a solid polymer electrolyte in an electrochromic device allowed us to study the lithium insertion reaction into $\mathrm{WO}_{3}$ and $\mathrm{V}_{2} \mathrm{O}_{5}$ under anhydrous conditions. The absence of humidity confers to the system a memory effect of several months. By impedance spectroscopy, the charge transfer and diffusion processes have been separated. The lithium chemical diffusion coefficient has been determined by a method which does not involve the value of the electrode surface area. These $\widetilde{D}$ values are found similar to those obtained with liquid electrolytes. The main difference introduced by the presence of a solid/solid interface is the low exchange current density at room temperature.

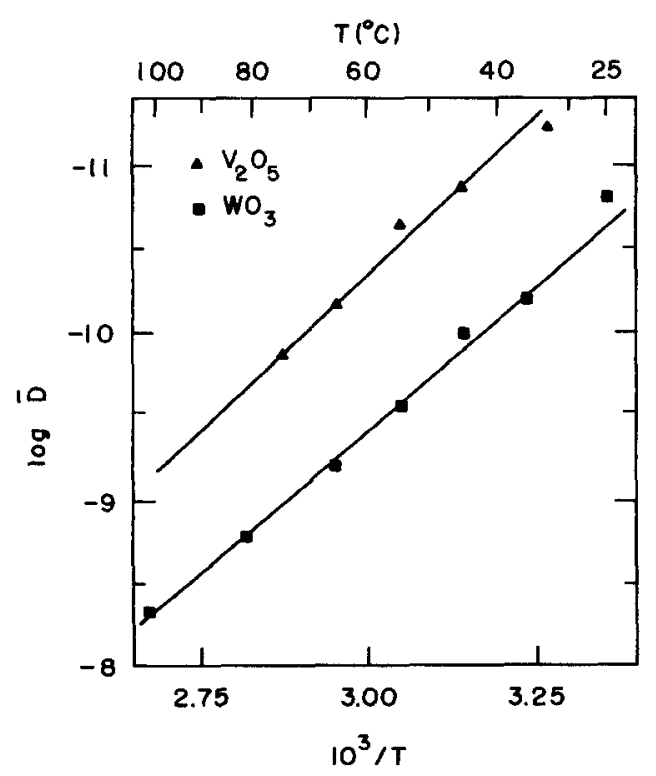

Fig. 13. Temperature dependence of $\bar{D}$ for $W \mathrm{O}_{3}$ and $\mathrm{V}_{2} \mathrm{O}_{5}$

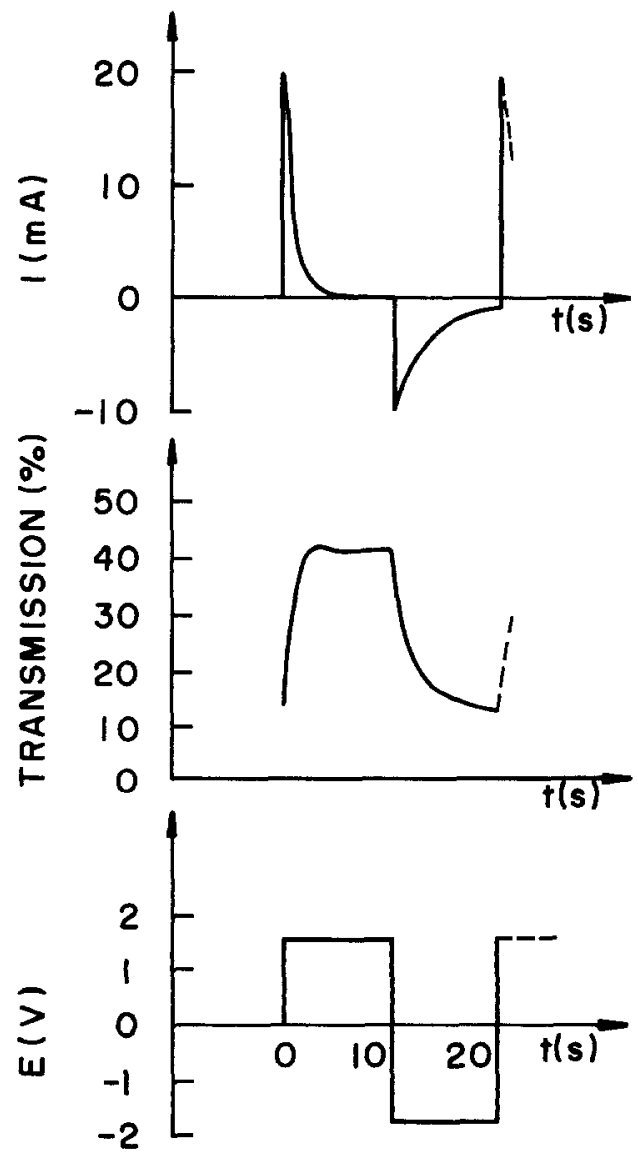

Fig. 14. 10,000th cycle of a potentionstatic test on a $\mathrm{WO}_{3} /$ $\mathrm{PEO}-\mathrm{LiN}\left(\mathrm{SO}_{2} \mathrm{CF}_{3}\right)_{2}$ electrochromic window transmission ot $\lambda=633 \mathrm{~nm}$.

Therefore, the importance of a good electrolyte/electrode contact has been underlined. This could probably be improved by using a polymer electrolyte of lower molecular weight. The feasibility of an all-solid-state $\mathrm{WO}_{3} / \mathrm{V}_{2} \mathrm{O}_{5}$ transmissive device has been demonstrated.

The main drawback remains the residual coloration in the bleached state (around 50\% of transmission). One possible explanation is difficulty in achieving complete deinsertion, probably due to the poor electronic conductivity of the fully oxidized $\mathrm{V}_{2} \mathrm{O}_{5}$ films. This problem may be difficult to overcome.

In order to improve the transmission characteristics and to obtain a reversible transparent counterelectrode exhibiting fast insertion kinetics, in our laboratory we have recently prepared mixed cerium titanium oxides layers by the dip-coating process with encouraging results (24). Multicomponent oxide layers can be obtained by this technique which can substitute for other physical methods of deposition in the search for an ideal counterelectrode.

\section{Acknowledgments}

The authors acknowledge the technical and financial support of Saint-Gobain Recherches in France and the financial help of CNPq in Brazil.

Manuscript submitted Feb. 27, 1990; revised manuscript received Aug. 14, 1990. This was Paper 627 presented at the Hollywood, FL, Meeting of the Society, Oct. 15-20, 1989.

Domaine University assisted in meeting the publication costs of this article.

\section{REFERENCES}

1. S. K. Deb, Appl. Opt. Suppl., 3, 192 (1969).

2. W. C. Dautremont-Smith, Displays, 3, 3 (1982).

3. C. M. Lampert, Solar Energy Mater., 11, 1 (1984).

4. R. D. Rauh, S. F. Cogan, and M. A. Parker, Proc. SPIE, 502, 38 (1984)

5. M. Greene, W. C. Smith, and J. A. Weiner, Thin Solid Films, 38, 89 (1976). 
6. S. K. Mohapatra, This Journal, 125, 284 (1978).

7. J. P. Randin and R. Viennet, ibid., 129, 2349 (1982).

8. M. B. Armand, J. M. Chabagno, and M. Duclot, "Fast Ion Transport in Solids," T. Vashita, Editor, p. 131, North Holland, New York (1979).

9. M. B. Armand, Solid State Ionics, 9-10, 745 (1983).

10. M. B. Armand, W. Gorecki, and A. Andreani, 11th International Conference on Polymer Electrolytes, Siena, Italia, June 14-16, 1989.

11. P. Donoso, W. Gorecki, C. Berthier, F. Defendini, and M. Armand, Solid State Ionics, 28-30, 1018 (1988).

12. R. D. Rauh and S. F. Cogan, ibid., 28-30, 1707 (1988).

13. S. F. Cogan, N. M. Nguyen, S. J. Perotti, and R. D. Rauh, Proc. SPIE, 1016, 57 (1988).

14. S. F. Cogan, N. M. Nguyen, S. J. Perotti, and R. D. Rauh, J. Appl. Phys., 66(3), 1333 (1989).

15. A. M. Anderson, C. G. Granquist, and J. R. Stevens, Proc. SPIE, 1016, 4-1 (1988).
16. M. B. Armand, Ph.D. Thesis, Grenoble (1978).

17. P. G. Dickens and G. J. Reynolds, Solid State Ionics, 5, 331 (1981).

18. S. K. Mohapatra and S. Wagner, This Journal, 125, 1603 (1978).

19. M. Nabavi, C. Sanchez, F. Tautelle, and J. Livage, Solid State Ionics, 28-30, 1183 (1986).

20. J. E. B. Randles, Disc. Faraday Soc., 1, 11 (1947).

21. C. Ho, I. D. Raistrick, and R. A. Huggins, This Journal, 127, 343 (1980)

22. A. J. Bard and L. R. Faulkner, Electrochimie, Masson Ed., 116 (1983).

23. B. Zachau-Christiansen, K. West, and T. Jacobsen, Solid State Ionics, 9-10, 399 (1983).

24. P. Baudry, A. C. Rodrigues, M. A. Aegerter, and L. O. Bulhoes, Proceedings of the Fifth International Workshop on Glasses and Ceramics from Gels, Rio de Janeiro, August 6-10, 1989.

\title{
An Electrochemical Investigation of the 1-Methyl-3-Ethylimidazolium Bromide Aluminum Bromide Molten Salt System
}

\author{
Jeffrey A. Boon and John S. Wilkes* \\ The Frank J. Seiler Research Laboratory, USAF Academy, Colorado 80840-6528
}

John A. Lanning

University of Colorado at Denver, Denver, Colorado 80204

\begin{abstract}
The electrochemical behavior of the room temperature molten salt made by combining 1-methyl-3-ethylimidazolium bromide and aluminum bromide was studied. It was found that the bromide system behaved, for the most part, analogously to the chloride counterpart. Bromide solvated in a room temperature molten salt is electrochemically similar to bromide in other nonaqueous solvent systems. The diffusion coefficients and the heterogeneous rate constants were determined for the bromide and tribromide species in the molten salt.
\end{abstract}

Although first used more than 40 years ago as an electrolytic bath for plating aluminum (1), room temperature molten salts have received renewed interest in recent years as electrolytes for battery applications. A molten salt electrolyte will theoretically increase the power density of a battery by not only decreasing the weight involved in the electrolyte system but also through the use of new couples which become feasible in a molten salt system.

We have described previously a battery cell that employs a rechargeable bromine-bromide electrochemical couple in the 1-methyl-3-ethylimidazolium chloride-aluminum chloride low-temperature molten salt (2). Preliminary experiments show that the electrochemistry of the brominebromide couple is complex, possibly due to halide exchange in the chloroaluminate melt. We report here a detailed electrochemical study of bromine and bromide in the chemically similar 1-methyl-3-ethylimidazolium bromide-aluminum bromide system.

Although Popov and Geske (3), among others, have characterized the nonaqueous electrochemical behavior of the different bromide-containing species, the chemical and electrochemical properties of the room temperature molten salts are different enough to warrant the investigation of bromide when it is solvated in the melt system.

\section{Experimental}

1-methyl-3-ethylimidazolium chloride (MEIC).-The MEIC was prepared by a method similar to that presented by Wilkes et al. (4). The procedure was changed to eliminate the high pressures involved in the reaction vessel by running the reaction at a lower temperature $\left(c a .30^{\circ} \mathrm{C}\right)$ for a longer time (ca. 2 weeks). The purity of the MEIC was confirmed by noting the lack of any unreacted 1-methylimidazole in the MEIC by ${ }^{1} \mathrm{H}$ NMR, and by noting the absence of the electrochemical reduction of any protonic impurity in a melt prepared from the MEIC.

1-methyl-3-ethylimidazolium bromide (MEIB).-The MEIB was prepared by a method similar to that described by Sanders et al. $(5,6)$. The only modifications was that the reaction was carried out in a round bottom flask with a reflux condenser attached. The reaction mixture was heated to keep the ethyl bromide refluxing. The purity of the MEIB was checked in a manner similar to that of the MEIC.

Aluminum bromide.-The aluminum bromide (Aldrich, $98+\%$ ) was purified by vacuum sublimation. The aluminum bromide was repeatedly sublimed until no color was observed in the collected material (a total of 3-5 sublimations).

Aluminum chloride.-The aluminum chloride was purified by the method described by Wilkes et al. (7).

Tetramethylammonium tribomide.-The tetramethylammonium tribromide was prepared by the method described by Chattaway and Hoyle (8) and characterized by UV-VIS spectroscopy as described by Buckles et al. (9).

The electrochemistry was carried out in a Vacuum Atmospheres Company dry box with a combined $\mathrm{H}_{2} \mathrm{O} / \mathrm{O}_{2}$ concentration of less than $10 \mathrm{ppm}$. The atmosphere in the dry box was UHP helium purified by a Vacuum Atmospheres MO-40 Dri-Train. The quality of the atmosphere 